\title{
Stroke from A Large Left Atrial Myxoma
}

\author{
Hitoshi Hirose $^{*}, 1$, Benjamin A. Youdelman ${ }^{1}$ and John W. C. Entwistle ${ }^{2}$ \\ ${ }^{I}$ Department of Surgery, Division of Cardiothoracic Surgery, Thomas Jefferson University, Philadelphia, PA; \\ ${ }^{2}$ Department of Cardiothoracic Surgery, Drexel University College of Medicine, Philadelphia, PA
}

\begin{abstract}
A 36-year-old male involved in a car accident was found to have an embolic stroke due to a left atrial myxoma. Open heart surgery was delayed 4 weeks to decrease the risk of neurologic complications from the anticoagulation required for cardiopulmonary bypass. After resection of the myxoma, intraoperative transesophageal echocardiography found severe mitral regurgitation, which was repaired.
\end{abstract}

Key Words: Myxoma, mitral valve disease, stroke, surgery.

\section{INTRODUCTION}

Neurologic complications resulting from cardiac myxomas are seen in $20-35 \%$ of patients [1, 2]. Embolic strokes may occur any time with progression of the tumor. Surgical resection is the definitive treatment for a myxoma. However, open heart surgery requires anticoagulation for cardiopulmonary bypass, and patients who have suffered a recent preoperative stroke are at increased risk for hemorrhagic conversion of a large embolic stroke. Delaying surgery for maturation of the embolic stroke decreases this risk. Here we present a young patient who was involved in a motor vehicle accident after having a stroke from his atrial myxoma. Surgery was delayed four weeks due to the recent large stroke.

\section{CASE PRESENTATION}

A 36-year-old-male with no significant medical history was brought into the emergency department by ambulance after being involved in a motor vehicle accident. He stated that he had experienced sudden onset of left sided numbness and weakness while driving, and lost control of the car. On admission, he was alert and oriented but had a mild expressive aphasia. His vital signs were stable. Heart sounds were regular with no murmur. The chest x-ray showed no signs of intrathoracic injury. The initial head CT scan was negative. No carotid stenosis was found by ultrasound. Transthoracic echocardiography showed left atrial mass and subsequently performed transesophageal echocardiography confirmed a large pedunculated mass in the left atrium protruding into the left ventricle though the mitral valve (Fig. 1). There was no mitral valve regurgitation. He was admitted to the intensive care unit for monitoring. Cardiothoracic surgical consultation was obtained.

A repeat head CT obtained 24 hours later showed a large acute infarct in the right middle cerebral artery distribution with diffuse surrounding edema (Fig. 2). There was a small

*Address correspondence to this author at the Department of Surgery, Division of Cardiothoracic Surgery, Thomas Jefferson University, 1025 Walnut Street College Building Room 605 Philadelphia, PA 19107, USA; Tel: 215925-4385; Fax: 215-925-4386; E-mail: genex@nifty.com lesion highly suggestive of hemorrhage within the infarcted area. The risk of hemorrhagic transformation of the stroke was considered to be high with heparinization for cardiopulmonary bypass, which is necessary for removal of myoxma, so surgery was postponed until the risk of neurological complication during open heart surgery become relatively low. Over the next 2 weeks in the hospital, he had persistent left sided hemiplegia; however, he did not develop any additional neurological events. He was discharged to a rehabilitation facility and electively scheduled for resection of the left atrial mass 4 weeks after the embolic stroke, when the risk of a catastrophic neurologic event from anticoagulation was considered to be reduced.

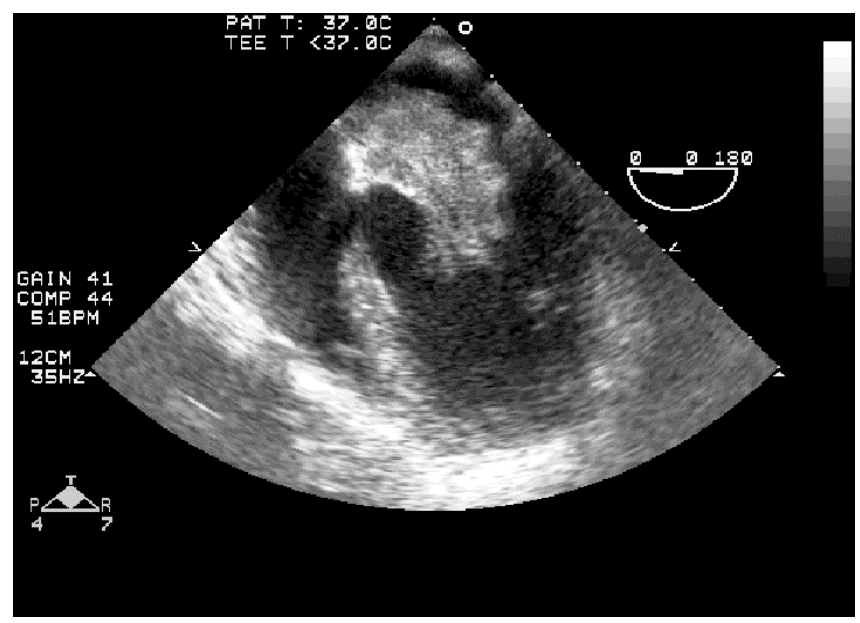

Fig. (1). Preoperative transesophageal echocardiography shows a large left atrial mass $(55 \times 40 \mathrm{~mm})$.

Through a midline sternotomy, the left atrial mass was approached via the groove of Sondergaard, after the patient received 300 units per $\mathrm{kg}$ of heparin for cardiopulmonary bypass. A left atrial tumor arising from the atrial septum was successfully resected (Fig. 3). The defect of the septum was repaired with an ePTFE patch. After resection of the left atrial tumor, intraoperative transesophageal echocardiography disclosed severe mitral regurgitation (Fig. 4). Cardiopulmonary bypass was reestablished, and the mitral valve 
was examined. The mitral valve was found to be moderately thickened with a dilated annulus. There was a large central regurgitant jet through poorly coapted mitral leaflets. The subvalvular apparatus appeared to be normal. Mitral annuloplasty was performed with a complete ring (Carbomedics $28 \mathrm{~mm}$ complete ring). With this ring annuloplasty, excellent coaptation of the mitral leaflet was achieved and there was no residual mitral regurgitation. The patient was weaned off cardiopulmonary bypass without difficulty. His postoperative recovery was uneventful. He was discharged to skilled nursing facility on postoperative day 10 . Pathological review of the specimen confirmed cardiac myxoma.

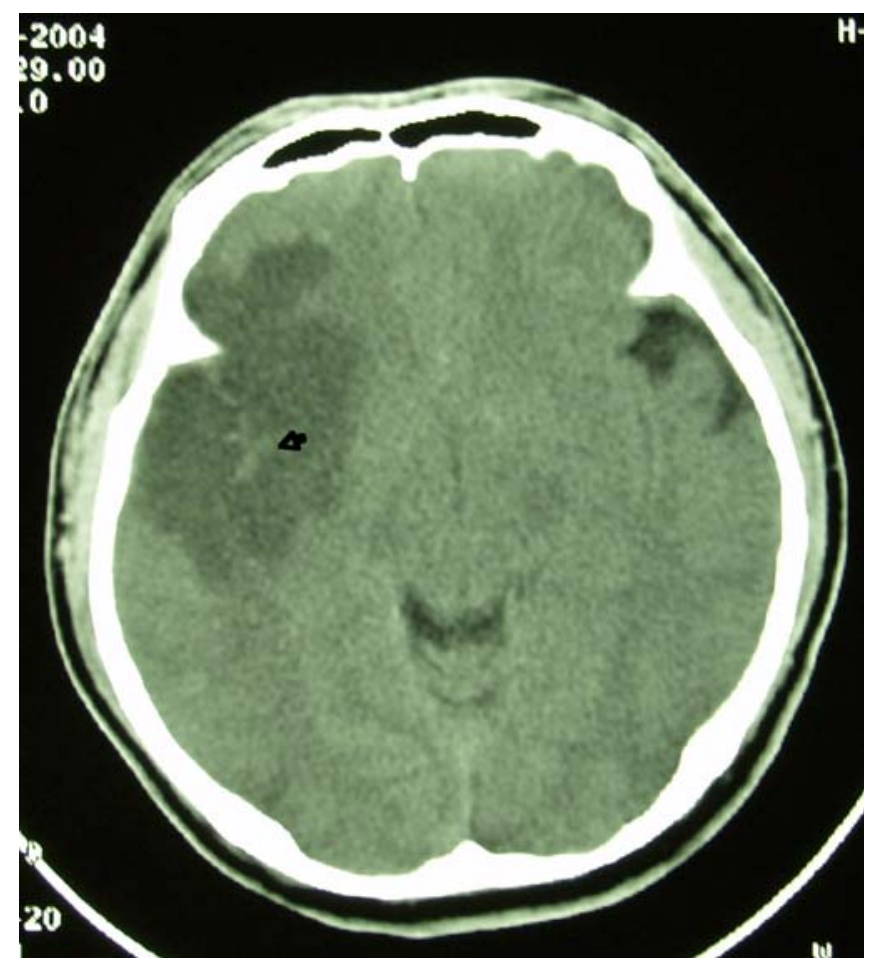

Fig. (2). CT scan of the head demonstrates a large infarct in the area of the right middle cerebral artery. There is a suggestion of hemorrhage within the infarcted area (arrow).
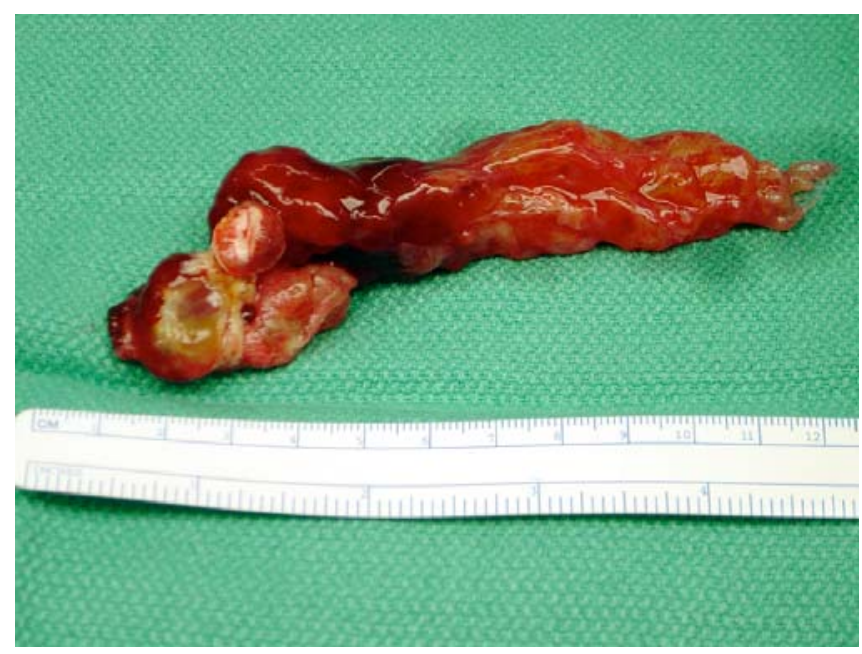

Fig. (3). Surgical specimen of the left atrial mass consistent with a large friable tumor.

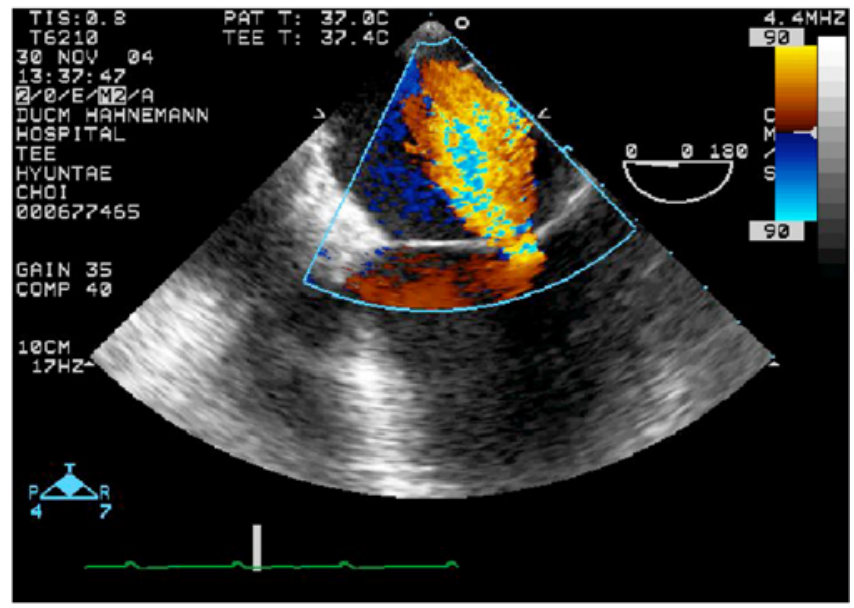

Fig. (4). Intraoperative transesophageal echocardiography after resection of the left atrial myxoma shows severe mitral regurgitation.

\section{DISCUSSION}

Cardiac myxoma is the most common benign cardiac tumor. About $75-90 \%$ of the cardiac myxomas occur in the left atrium, and are found more commonly in the 5th or 6th decades of life [3-5]. Neurological manifestations are one of the most common presentations, although half of these neurological events are reversible, such as syncope, dizziness, or headache [1]. A recent study reported that embolic stroke was observed in $9-22 \%$ of atrial myxomas $[2,3]$. Tumor emboli are not related to size, $[2,3]$ but instead are related to the mobility and friability of the tumor [2-6]. The overlying thrombus on the surface of the myxoma plays a role in the embolic phenomena, rather than tumor itself $[3,6]$.

Resection of an atrial myxoma without a recent stroke is relatively simple operation. However, the systemic anticoagulation required for cardiopulmonary bypass may become an issue in the patient who has suffered a recent stroke. A large embolic stroke may become hemorrhagic and may extend brain damage, especially during the first week after a stroke [7]. The large dose of anticoagulation required for cardiopulmonary bypass may trigger hemorrhagic transformation. There is no clear guideline indicating the safe interval from the onset of stroke to the time of the surgery $[1,6]$. However, a study showed the mortality rate among patients who undergo open heart surgery with a recent embolic stroke became considerably reduced if the surgery was postponed more than 4 weeks after the embolic neurologic event [8].

Mitral valve regurgitation related to atrial myxomas is rare, as recently summarized by Whitlock [9]. The mitral regurgitation in our case could be related to the mechanical stretch of the annuls by chronic prolapse of the large atrial mass thought the mitral valve into the left ventricle. Preoperative echocardiography failed to demonstrate mitral regurgitation, possibly due to the presence of the large atrial mass occupying the space between the mitral leaflets. Removal of the mass uncovered a severe central jet through noncoapting mitral leaflets. Monitoring of intraoperative transesophageal echocardiography played important role in the detection of the mitral valve regurgitation, which became significant after removal of myxoma [10]. Because of annular dilatation, 
minimal valvular abnormalities and a normal subvalvular apparatus, the valve was successfully repaired.

\section{REFERENCES}

[1] Ekinci EI, Donnan GA. Neurological manifestations of cardiac myxoma: a review of the literature and report of cases. Intern Med J 2004; 34: 243-9.

[2] Pinede L, Duhaut P, Loire R. Clinical presentation of left atrial cardiac myxoma. A series of 112 consecutive cases. Medicine 2001; 80: 159-72.

[3] Aggarwal SK, Barik R, Sarma TC, et al. Clinical presentation and investigation findings in cardiac myxoma: new insights from the developing world. Am Heart J 2007; 154:102-7.

[4] Shapiro LM. Cardiac tumors: diagnosis and management. Heart 2001; 85: 218-22.

[5] O'Rourke F, Dean N, Mourandian MS, Akhtar N, Shuaib A. Atrial myxoma as a cause of stroke: case report and discussion. Can Med J Assoc 2003; 169: 1049-51.
$[6]$

Lee VH, Connolly HM, Brown RD Jr. Central nervous system manifestations of cardiac myxoma. Arch Neurol 2007; 64: 111520.

[7] Toni D, Fiorelli M, Bastianello S, et al. Hemorrhagic transformation o brain infarct: Predictability in the first 5 hours from stroke onset and influence on clinical outcome. Neurology 1996; 46: 3415.

[8] Eishi K, Kawazoe K, Kuriyama Y, Kitoh Y, Kawashima Y, Omae T. Surgical management of infective endocarditis associated with cerebral complications. Multi-center retrospective study in Japan. J Thorac Cardiovasc Surg 1995; 110: 1745-55.

[9] Whitlock R, Evans R, Lonn E, Teoh K. Giant left atrial myxoma and associated mitral valve pathology. J Cardiothorac Vasc Anesth 2007; 21: 103-5.

[10] Mastushita T, Huynh AT, Singh T, Hayes P, Armarego S, Seah PW. Mitral valve annular dilatation by left atrial myxoma. Heart Lung Circ 2008; Jan 3 [Epub ahead of print].

(C) Hirose et al.; Licensee Bentham Open.

This is an open access article licensed under the terms of the Creative Commons Attribution Non-Commercial License (http://creativecommons.org/licenses/by$\mathrm{nc} / 3.0 /$ ) which permits unrestricted, non-commercial use, distribution and reproduction in any medium, provided the work is properly cited. 